\title{
WHAT DO ICONICITY JUDGEMENTS REALLY MEAN?
}

\author{
Hannah Little ${ }^{1}$ and Justin Sulik ${ }^{2}$ \\ *Corresponding Author: hannah.little@uwe.ac.uk \\ ${ }^{1}$ University of the West of England, Bristol. \\ ${ }^{2}$ Royal Holloway, University of London. justin.sulik@gmail.com
}

Iconicity is a central topic in language evolution research. It has been studied as a tool for bootstrapping communication systems (Fay et al., 2013), as an emergent property (Tamariz et al., 2017), and as a confound in the emergence of structure (Verhoef et al., 2016). Here, we illustrate potential issues with methods used to measure iconicity in language evolution experiments, both those identified in existing published examples, and present two new case studies. We specifically focus two confounds: world knowledge and modality-specific effects of salience.

Iconicity judgements fall into two broad classes. One method is to have naïve participants match a signal with a meaning from an array (Perlman et al., 2015). If a signal is iconic, then participants are more likely to match it with its intended meaning than with other meanings. Another method is to ask participants to rate how well the signal resembles its referent (Perry et al., 2015).

Previously discussed confounds in iconicity judgement tasks include language knowledge, and the instructions given to participants providing the iconicity judgements. Occhino et al. (2017) looked at the difference between iconicity judgements given for existing signs in both American Sign Language and German Sign Language by native signers of each language. They found that participants rated signs from their native languages as being significantly more iconic than signs in the other language. Ortega et al. (2017) showed that spontaneous gestures that have overlap with linguistic signs are rated more iconic by native signers than by non-signers. These results show that linguistic knowledge has a significant effect on how participants respond in rating experiments. Perry et al. (2015) explored the effects of different sets of instructions in rating tasks. They found that specific words are judged to be more iconic when participants are asked to rate how likely an alien is to guess the meaning of a word, compared to simply rating resemblance between words and meanings. Importantly, context can also contribute to a word being guessable. For example, the first thing someone says on meeting you being a greeting is guessable regardless of how iconic the signal is.

In our first case study (Sulik, 2018), we present data from a graphical signalling task based on Fay et al. (2010). Iconicity ratings represent how well the 
signal resembles the referent. While the results, discussed above, from Occhino et al. (2017) focus on language knowledge, the current study focuses on world knowledge. At first glance, the results from (Sulik, 2018) suggest there is a significant effect of iconicity on success: the more iconic the signal, the more likely participants were to guess its meaning. However, we show that the iconicity ratings represent a fairly superficial predictor of performance, and that a better predictor of success is a measure of the complexity of the relevant world knowledge. Some representations are relatively simple (there is one obvious way to construe something; people share that construal). Other representations are more complex (people don't share intuitions about which of several construals is the most salient). The conclusion here is not that iconicity ratings are uninformative or misguided, but rather that the iconicity of a signal is tightly bound up with the world knowledge motivating that signal. Thus, a statistical relationship between iconicity ratings and performance does not necessarily mean that iconicity explains performance. The take-home message is that language evolution experiments that rely on iconicity ratings should control for the complexity of the relevant meanings, and we illustrate one simple way to control for this.

In our second case study, we discuss a matching task. (Little, Eryılmaz, \& Boer, 2017) used a forced-choice matching task to measure iconicity in artificial signals produced during a communication game, where participants were asked to select a signal's meaning from 4 choices. Some signals were more commonly correctly matched with their referents than others, indicating that those signals were more iconic. Here, we present new data on how many times listeners clicked on particular meanings in the playback experiment, regardless of what the correct meaning was. This data is useful to investigate whether some meanings are simply selected more often overall because they lend themselves particularly well to the iconicity afforded by the particular modality being used. While we find that there was no correlation between how often signals were clicked overall and how often they were correctly matched by naïve listeners, some meanings were clicked on substantially more often than others, indicating that participants thought many signals resembled those particular meanings. We interpret this as an effect of modality, cohering well with previous findings. For example, in a forced-choice task, participants were more likely to interpret gestures as verbs than nouns because gesture is an action-orientated modality (Micklos, 2017). An alternative interpretation is that some meanings may be chosen more than others just because that meaning is very salient and attracts participants' attention. Regardless of interpretation, the affordances of the modality used in the experiment can cause some meanings to be chosen more than others. Accordingly, we urge that matchingbased language evolution experiments control for choice frequency.

Overall, we present evidence that extends previously observed knowledge- and modality-based confounds, and highlight ways in which experiments studying the effect of iconicity on communication can correct for these confounds. 


\section{References}

Fay, N., Arbib, M., \& Garrod, S. (2013). How to bootstrap a human communication system. Cognitive Science, 37(7), 1356-67.

Fay, N., Garrod, S., Roberts, L., \& Swoboda, N. (2010). The interactive evolution of human communication systems. Cognitive Science, 34, 351-386.

Little, H., Eryılmaz, K., \& Boer, B. de. (2017). Conventionalisation and discrimination as competing pressures on continuous speech-like signals. Interaction studies, 18(3), 355-378.

Micklos, A. (2017). Iconic strategies in silent gesture: Perceiving the distinction between nouns and verbs. In 11th international symposium on iconicity in language and literature (pp. 26-27).

Occhino, C., Anible, B., Wilkinson, E., \& Morford, J. P. (2017). Iconicity is in the eye of the beholder. Gesture, 16(1), 100-126.

Ortega, G., Schiefner, A., \& Ozyurek, A. (2017). Speakers gestures predict the meaning and perception of iconicity in signs. In G. Gunzelmann, A. Howes, T. Tenbrink, \& E. Davelaar (Eds.), the 39th annual conference of the cognitive science society (cogsci 2017) (p. 889-894).

Perlman, M., Dale, R., \& Lupyan, G. (2015). Iconicity can ground the creation of vocal symbols. Royal Society open science, 2(8), 150152.

Perry, L. K., Perlman, M., \& Lupyan, G. (2015). Iconicity in english and spanish and its relation to lexical category and age of acquisition. PloS one, 10(9), e0137147.

Sulik, J. (2018). Cognitive mechanisms for inferring the meaning of novel signals during symbolisation. PLOS ONE.

Tamariz, M., Roberts, S. G., Martínez, J. I., \& Santiago, J. (2017). The interactive origin of iconicity. Cognitive Science.

Verhoef, T., Kirby, S., \& Boer, B. (2016). Iconicity and the emergence of combinatorial structure in language. Cognitive science, 40(8), 1969-1994. 